This is an electronic reprint of the original article. This reprint may differ from the original in pagination and typographic detail.

Author(s): Westerholm, Kirsi; Räsänen, Anne

Title: $\quad$ Sharing and promoting disciplinary competences for university teaching in English: voices from the University of Jyväskylä language centre's TACE programme

Year: $\quad 2015$

Version:

Please cite the original version:

Westerholm, K., \& Räsänen, A. (2015). Sharing and promoting disciplinary competences for university teaching in English: voices from the University of Jyväskylä language centre's TACE programme. In J. Jalkanen, E. Jokinen, \& P. Taalas (Eds.), Voices of pedagogical development : expanding, enhancing and exploring higher education language learning (pp. 131-157). Research-publishing.net. https://doi.org/10.14705/rpnet.2015.000290

All material supplied via JYX is protected by copyright and other intellectual property rights, and duplication or sale of all or part of any of the repository collections is not permitted, except that material may be duplicated by you for your research use or educational purposes in electronic or print form. You must obtain permission for any other use. Electronic or print copies may not be offered, whether for sale or otherwise to anyone who is not an authorised user. 


\title{
7 Sharing and promoting disciplinary competences for university teaching in English: voices from the University of Jyväskylä language centre's TACE programme
}

\author{
Kirsi Westerholm ${ }^{1}$ and Anne Räsänen ${ }^{2}$
}

\section{Abstract}

$\mathrm{T}$ he internationalisation of universities often means that the language of learning and teaching needs to be changed - at present most commonly to English. Apart from English-speaking countries, then, most European universities offer their degree programmes in a language that is not the first language of either the students or the teachers. This challenging situation is also the reality in Finland and at the University of Jyväskylä. Many Finnish universities have set up supporting infrastructures to deal with the new challenges, particularly in their international master's programmes. In this article we describe the TACE programme, which has been run by the Language Centre on an annual basis since 2010, and in a modular form since 2005. Starting with the framework, rationale and research-based framework for our TACE programme in intercultural university pedagogy, we then move to describe its content and practices as well as report some 'voices from the floor', that is, perceptions and experiences of the interdisciplinary and international group of teaching staff who have participated in the programme. Finally, some concluding remarks, challenges and benefits are presented.

Keywords: internationalisation, English-medium higher education, staff development, pedagogical development, teaching academic content through English.

\footnotetext{
1. Language Centre, University of Jyväskylä, Finland; kirsi.westerholm@jyu.fi

2. Language Centre, University of Jyväskylä, Finland; anne.e.rasanen@jyu.fi
}

How to cite this chapter: Westerholm, K., \& Räsänen, A. (2015). Sharing and promoting disciplinary competences for university teaching in English: voices from the University of Jyväskylä language centre's TACE programme. In J. Jalkanen, E. Jokinen, \& P. Taalas (Eds), Voices of pedagogical development - Expanding, enhancing and exploring higher education language learning (pp. 131-157). Dublin: Research-publishing.net. doi:10.14705/rpnet.2015.000290 


\section{Introduction}

The internationalisation of higher education (HE) in Finland has been one of the core strategies of national internationalisation policies. According to the Ministry of Education strategy for 2009-2015 regarding internationalisation in HE (Finnish Ministry of Education 2009), internationalisation is needed for societal renewal, for promoting diversity and networking, and for national competitiveness and innovativeness in general. This policy provides the general national guidelines to be implemented at the institutional level. For obvious reasons, promoting Finnish higher education and mobility internationally has resulted in changing the language of instruction from Finnish or Swedish to English. According to the 2012 evaluation of international degree programmes by the Finnish Higher Education Evaluation Council (Välimaa et al. 2013), there were 257 English-medium programmes at universities, with 98\% at the master's level. Although there were no major differences in the way that these programmes were launched, implemented, managed or evaluated in comparison to the domestic programmes, English language proficiency and pedagogical skills were emphasised in the evaluation because full degree programmes tend to have higher stakes than do short-term mobility or individual English-medium courses.

A recent ACA study (Wächter \& Maiworm 2014) lists Finland as having the highest percentage ( $82 \%$ ) of HE institutions in Europe to offer English-medium master's programmes. As in the other Nordic countries, the main reasons behind this are to attract foreign students, to improve the intercultural competence and skills of domestic students, and to promote the international profile of the institution and in this way also foster networking and partnerships in research and education. The main challenges brought by the multilingual and multicultural classroom in institutions with entry requirements in language proficiency relate to students' academic skills, learning styles, level of content knowledge, academic practices, and varying ethical standards. And yet, as Wächter and Maiworm (2014) report, support of either students or of teachers is not common in the other Nordic countries, whereas $78 \%$ of Finnish institutions offer language and study support to students and many also provide staff support. 
Changing the language of learning and teaching is not a straightforward process, but one that affects all parties involved. For the institutions, it means that new policies and guidelines will be needed to accommodate the new international dimension of the student body, curricula and counselling in order to ensure the quality of the education and the image of the institution. For the teachers, an international classroom requires management of heterogeneous backgrounds and skills in language, content matter and culture, in addition to competence in facilitating and promoting disciplinary learning in a foreign language. The students, then, are required to handle conceptually demanding academic language in a new learning community characterised by new academic practices and demands for increased tolerance of uncertainty and intercultural communication skills. It is to meet these challenges that the support systems at the University of Jyväskylä were established.

The aim of the present article is to give an account of the rationale, content and experiences of the staff development programme in intercultural university pedagogy offered by the University of Jyväskylä Language Centre. The 10/15 ECTS credit TACE programme has been offered on an annual basis since 2010 and in a modular form since 2005. The institutional framework, set up to implement the national strategies concerning, for example, English-medium higher education, is introduced first, followed by an explanation of the researchbased rationale of TACE. The content and practices of the programme are then outlined, accompanied with some 'voices from the floor', that is, the perceptions and experiences of the interdisciplinary and international group of teaching staff who have participated in the programme. Finally, some concluding remarks, challenges and benefits are presented.

\section{Institutional framework}

Two institutional policies of the University of Jyväskylä are behind the staff development programme TACE, namely the University of Jyväskylä (JYU) Language Policy $(2004,2012)$ and the requirement, as of 2010, for all staff appointed in positions involving teaching to have university pedagogical 
training within two years of their appointment if they have not previously had it. This latter policy is not specific to teaching in English but to teaching in general. The JYU Language Policy, however, specifies the kinds of pedagogical and English communication and language skills that teaching and counselling staff must have for teaching in international classrooms. It states that

"Teachers and counsellors of multilingual and multicultural student groups are expected to be proficient in the language of instruction (minimum level $\mathrm{C} 1$ in the Common European Framework of Reference for Languages) as well as to have developed intercultural competence" (University of Jyväskylä 2012: 5).

"Language plays a more prominent role in knowledge and competence building when teaching and learning is done through a foreign language, rather than in the mother tongue. This requires special awareness from the teacher, as well as mastery of intercultural pedagogy and guidance in the language of instruction. ... The communication skills and intercultural competences of both teachers and counsellors will be systematically developed and also taken into account in recruitment and in the appraisal system" (University of Jyväskylä 2012: 8).

The action plans for the JYU Language Policy further state that the quality of teaching in English is systematically ensured, that tailored staff development is provided, and that the language quality of students' English-medium research communication, theses and dissertations is systematically attended to. Similar actions were recommended in the internal evaluation of the master's programmes in 2014.

The policies indirectly acknowledge the fact that language proficiency and pedagogical competence are intertwined in good teaching, and that a mere language test is not sufficient in evaluating the qualifications for teaching in a foreign language - a fact that has been suggested in various studies (see e.g. Airey, Lauridsen, Räsänen, Salö \& Schwach Forthcoming; Dafouz \& Núnẽz 2009; Klaassen 2001, 2008; Kling \& Staehr 2011, quoted in Unterberger 
2012; Pilkinton-Pihko 2013; Räsänen \& Klaassen 2006). Nor is a language test alone enough to ensure that the competence of students is adequate for the conceptual academic level of language use in their discipline, although it is necessary for setting the threshold level at entry to a master's programme, for example.

\section{Rationale for staff development in English-medium instruction}

The challenges that both students and teachers face in a multilingual and multicultural classroom are already well documented. In general, students should graduate as new experts in their fields, and teachers should facilitate their construction of expertise through interactive pedagogical designs and agency. Both these processes are conducted through language (see Wells 2002). However, as indicated by Räsänen \& Klaassen (2013) “an international classroom [automatically] implies heterogeneous backgrounds and skills in language, content and culture. Added to this is the awareness (or non-awareness) of the content specialist in terms of the linguistic and cultural characteristics of the discipline being taught as well as of how language choice might affect knowledge building and knowledge structures in that discipline" and how all this could be promoted using appropriate pedagogical approaches and practices. These issues provide the essence of the research-based rationale behind the TACE programme, detailed in this section.

\subsection{From student to expert}

Academic experts are people who are recognised as such on the basis of how they communicate their expertise to other people - whether within their own disciplinary group, within cross-disciplinary groups or as members of society in general. It is through this communication that their professional status becomes transparent to others, in other words, they are able to use the language of the discipline at the conceptual level that is required in different situations. Hyland (2012) refers to this in stating that "an academic identity is who the 
individual is when acting as a member of a discipline' and that 'an engineer is an engineer because he or she communicates like one and the same is true for biologists, historians and linguists" (Hyland 2012: 25). They have learned the language of their field through studying and interacting with previous experts in the field. Their teachers have structured the content of the discipline by using various kinds of pedagogical methods, thus engaging them in building their knowledge and expertise in the field. At the same time, they have gradually learned to use the kind of language that is typical of that discipline as well as whether the discipline could be characterised as one with explicit notions and truths or perhaps one with many angles and possible answers, and therefore also more variable and ambiguous in its language (see also Airey 2009). This process of becoming an academic expert is similar regardless of whether the language used is one's mother tongue or some other language. However, in the former case, little attention is usually given to making the necessity of the integration of language and content explicit, because the prerequisites for learning a new communication register and new discourse conventions are assumed to be in place. In the latter case, however, more awareness and attention are needed to facilitate and scaffold learning, which is particularly obvious in an international classroom where the language of instruction may be foreign for both teachers and students.

It is most often the case that the multilingual and multicultural student group is studying in English in a new academic and cultural context. It is possible that they have little experience in using discipline-specific English and, in many cases, no experience in writing academic papers in English. Therefore, the students are "required to transition from everyday language use to conceptually demanding academic language use" (Räsänen 2011: 156, see also Cummins 1984 on the move from basic interactive communicative skills, [BICS] to cognitive academic language proficiency [CALP]).

It is also possible that academic cultures and practices differ greatly between their home environment and the new environment, thus making it necessary "to enter a learning community characterised by demands for increased tolerance of uncertainty and intercultural communication skills" (Räsänen 2011: 156). 
However, the expectations of achievement are usually the same for all students regardless of the language of instruction. Across their studies - and in degree programmes in particular - students are expected to have the capacity to combine linguistic, pragmatic and previously gained background knowledge in the understanding and construction of the new knowledge in their disciplinary field and ability to use appropriate strategies in completing the required learning tasks. Furthermore, they need to be able to monitor, assess and direct their own learning in the way needed. They should have the capability to process, analyse and evaluate conceptual-level information and to draw conclusions, solve problems and compile syntheses. Moreover, they are expected to participate in class discussions and seminars, work purposefully in intercultural teams and to give presentations as well as write reports that indicate their progress in disciplinary expertise. All this is what we expect as higher education professionals. The students, on the other hand, expect teachers to be able to make it all possible, without of course detailing it in this way. To fulfil these expectations, both parties need to have certain well-developed and specific skills and abilities, sometimes referred to as 'operational competence' or 'knowing how', as opposed to 'knowing what' (Light \& Cox 2001: 8; Räsänen \& Klaassen 2006: 256). And the operational competence required has to become manifest in a new language. Regardless of this, language and communication development is seldom included in the expected learning outcomes or curricula of, for example, master's programmes taught in English, but rather, they are seen to grow as incidental learning because of the medium of instruction. There are, however, preconditions to be met for 'picking up the language', which makes the absence of attention to the role of language a serious quality issue in English-medium instruction (see e.g. Hellekjaer 2007; Räsänen \& Klaassen 2006; Shaw 2013; Wilkinson 2008).

Discipline specialists (i.e. HE content teachers) at their best are competent in the use of the new instructional language at the conceptual level that is required and often consider the use of a so-called simpler language a sign of watering down the content and not expressing it properly. In other words, they are able to transfer their way of speaking about the discipline to a new language but consider that the discipline requires a certain level of thinking and expression 
in order to remain a discipline. They might also be able to transfer and adapt their teaching skills to the new situation on the basis of their experience, and provide the kind of scaffolding that the multilingual and multicultural group requires - often intuitively and without explicit attention to, or awareness of, the role of language in the process. Thus, when they notice students having problems, they modify their slides, check comprehension more specifically, use clear structuring, provide more handouts and instructions, change their learning tasks and so on. In this way, the good pedagogical skills compensate for, and complement, the conceptually complex language use of the discipline and facilitate learning in a multilingual and multicultural classroom. However, there are other issues that require attention. Construction of knowledge differs between disciplines and languages, and different disciplines tend to have preferred academic practices that teachers use in their own teaching. In certain cases, specific actions must be taken to make the role of language explicit for both teachers and students in information management, knowledge construction and expression, and professional communication in order to provide the kind of a learning environment that becoming an academic expert requires (see e.g. Airey 2009; Parpala, Lindblom-Ylänne, Komulainen, Litmanen \& Hirsto 2010; Shaw 2013; Wells 2002).

\subsection{Dimensions of culture in a multilingual and multicultural classroom ${ }^{3}$}

Although cultural issues have only become clearly salient features of European academic communities and significant topics for research more recently, multilingual and multicultural classrooms have existed and been studied in other parts of the world for much longer. In addition to numerous studies on ethnic cultures (see e.g. Palfreyman \& McBride 2007), Flowerdew and Miller (1995) suggested nearly twenty years ago already there are several cultural issues that tend to cause problems to student understanding in multilingual and multicultural classrooms. As illustrated in Figure 1 below, four dimensions of culture that are present in such a class were identified.

3. This section is adapted from Räsänen 2011 
Figure 1. Dimensions of culture in a multilingual and multicultural class (adapted from Flowerdew \& Miller 1995 and Räsänen 2011)

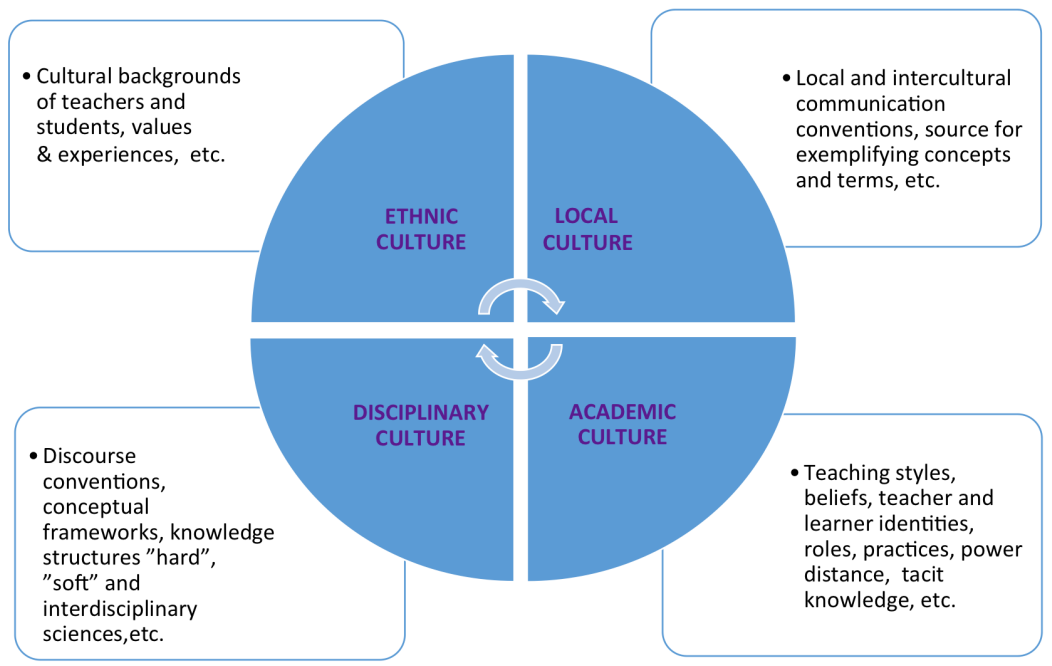

All these dimensions are integrated in the TACE programme on an across- thecurriculum principle. The main focus, however, is on disciplinary culture and its relation to academic culture and academic practices, because it is there that the integration of content, language and discourse needs more specific attention and awareness.

As was indicated above, an academic and disciplinary expert is able to use the discourse conventions which are typical of his/her specific field and profession, whatever the language involved. Räsänen (2011: 158) further mentions that,

"[a]ccording to some studies (e.g. Hyland 1999) the traditional distinction between 'hard' sciences and 'soft' (or 'interdisciplinary') sciences [also shows] in the ways in which knowledge is structured in these sciences and in which way it is constructed within the social practices of their discourse communities. Thus, following Hyland (1999: 121), communicating as [some academic] professional means 'being able to construct an argument 
that meets field-specific standards of these respective disciplines', as well as reflects the kinds of social practices (e.g. academic writing in the first person singular vs. using the passive voice) that [belong to] these disciplinary cultures. [Furthermore,] for the same reason, there tend to be [preferences in the] academic practices and teaching styles [that are followed in those cultures], characterising the basic differences in disciplinary knowledge construction, [namely,] hierarchical and cumulative knowledge building (often with one correct answer based on existing facts and hard evidence) vs. interpretative and negotiated knowledge building (with many answers, classifications, and paradigms). The former tends to prefer transmissiontype lecturing followed by application, whereas the latter tends to prefer dialogical and interactive type of teaching".

Along the same lines, Neumann, Parry and Becher (2002) characterise pure hard disciplines (e.g. physics) as having an atomistic knowledge structure and being concerned with universals, whereas pure soft disciplines are individually interpretative with no clear knowledge community. As regards the students of the various disciplines, then, Parpala et al. (2010; see also Parpala, LindblomYlänne \& Rytkönen 2011), among others, have reported that students' approaches to, and experiences of, the teaching-learning environments as well as their conceptions of good teaching and the teachers' role in facilitating learning in different disciplines vary accordingly. These studies concerned learning in the mother tongue, not in a foreign language.

Becoming an academic expert necessarily involves knowledge construction and sharing, as well as conceptual-level communication. For these reasons it is essential for content teachers to be aware of the characteristics and preferences of their disciplines so that they are able to act as 'role models' for their students in this respect. Added to this in an international classroom is the fact that the medium of instruction and learning might be a foreign language for all, with its own way of expressing knowledge construction and disciplinary expertise. Therefore, besides being able to analyse and assess the cognitive load of their concepts, teachers should also be aware of whether their discipline in general is linguistically complex or not. Moreover, the lexical range of the discipline 
potentially affects the kind of discourse competence required from teachers and future experts, for example, in terms of whether the terminology of the discipline can be explicitly defined or vague and culturally loaded. This kind of reflection and sharing with colleagues and students - all part of the practices in the TACE programme - contributes greatly to everybody's understanding of what teaching and learning through a foreign language actually requires (Räsänen 2011).

In the following section, the details of the TACE programme, its module contents and expected learning outcomes are described in the light of the theoretical considerations and rationale above and accompanied by participant voices and reflections. The main practices and assignments for each module are also introduced.

\section{TACE modules and participants' voices}

As was explained above in the introduction, TACE is a staff development programme in intercultural university pedagogy and English provided by the University of Jyväskylä Language Centre. The programme was designed to meet the needs and challenges of both the domestic and international staff with teaching and guidance responsibilities and possibly no particular pedagogical qualifications. Since the beginning of the present form of TACE in 2010, some 15-20 staff members per year have completed the programme, 20 being the number accepted annually. They have represented all of the seven faculties of the university, and thus the group is each year multidisciplinary, multilingual and multicultural with approximately one third of international and two thirds of Finnish discipline specialists. Three English lecturers of the Language Centre form the permanent team of instructors. The programme is separately funded and part of the University's staff development provision for enhancing the quality of teaching.

Figure 2 below illustrates the TACE programme modules, which are flexible in that they are partially overlapping and adjusted to the needs and wishes of each participant group. The total extent of the programme is 10/15 ECTS 
credits, depending on the development project that each participant wishes to complete. TACE itself follows an integrated approach of addressing issues specific to both the language and the teaching of the discipline. The programme begins and finishes with an intensive day, with bimonthly contact sessions in between, and in this format runs for approximately eight months. Each teacher is also observed in action, in other words, visited by one of the trainers and provided with individual feedback and consultation. Furthermore, feedback on language and related issues is given on the written distance tasks as well as on, for example, pronunciation based on videoed presentations.

Figure 2. TACE programme modules

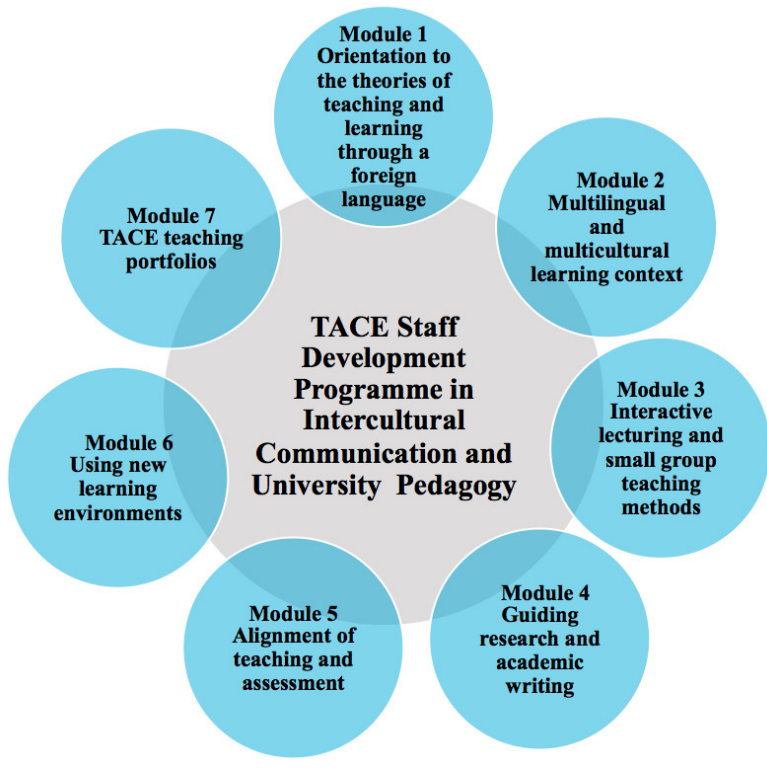

The TACE programme is often described in the participants' written work and comments as a journey. Across the programme, the TACE teachers have a variety of distance assignments (e.g. a critical review or a position paper), reflective blog posts after each contact session and a development portfolio where they discuss their experiences, insights and learning process as well as their teaching 
philosophy. These tasks and activities have been aligned with the expected learning outcomes for both content and language, including, for example, mapping of student needs and experiences, matching pedagogical approaches to student skills, analysing the requirements of one's own discipline, adapting task designs and assessment criteria, revising instructions for assignments, and guiding and giving feedback to students.

In what follows, the content of each module and the expected learning outcomes as well as examples of activities and assignments are presented briefly. This is accompanied by reflections of the participants extracted verbatim from their blog posts and portfolios, both of which are compulsory elements in the programme.

\subsection{Module 1: orientation and formulation of learning outcomes}

The first thematic module of the TACE programme introduces and explains the expected learning outcomes of the programme as well as establishes a theoretical background to teaching and learning through English in higher education settings. The TACE website and the blogging expected are also introduced. An important expected learning outcome is to understand the special features and requirements of teaching and learning through a foreign language. In the sessions, the TACE context is reflected upon from the perspective of the participants (i.e. their disciplines and backgrounds) and from that of their students' background: who they are, where they come from and what their cognitive, disciplinary and linguistic skills and previous experiences are. The dimensions of four cultures - ethnic, local, academic and disciplinary (Flowerdew \& Miller 1995) - are explored in the participants' contexts. The concepts of an academic expert and the role of language in becoming one are discussed. Furthermore, the challenges and impact of English-medium instruction in the non-English context for both teachers and learners as well as for the entire institution are investigated. In the discussions and workshops the TACE participants usually raise such issues as the need for new pedagogical skills, approaches and focuses, and new requirements for intercultural communication competence (i.e. new teacher profiles) as teachers and role models of both content and disciplinary language and discourse. 
"Unfortunately the linguistic proficiency aspect is often a secondary concern for the curriculum planners, course designers and teachers who are mainly subject teachers and proficient users - not trained teachers - of a foreign language".

“These [master's level] courses should be designed carefully and keeping the learning objectives in mind and would profit from professional dialogue with language teachers especially when course assignments and tasks are prepared".

"During the TACE module I have updated the learning outcomes I use in my courses so that they include not only content but also language skills".

\subsection{Module 2: multilingual and multicultural learning context}

As was suggested above, an international classroom with students and teachers from different ethnic, academic and disciplinary cultures requires a set of intercultural competences accompanied by pragmatically correct use of English as a lingua franca for instructional purposes and learning. This module focuses on how to attend to critical incidents, how to use diversity as an asset in a multilingual and multicultural HE classroom, and how to take into account the special needs of international students in promoting their learning. Therefore, the expected learning outcomes designed for this module include managing group dynamics with intercultural students, intercultural communication competence, surveying academic practices in multilingual and multicultural settings and attending to learning styles and study skills (see Joy $\&$ Kolb 2009). TACE addresses these issues from several viewpoints. Some of the most prominent theories and definitions of culture are discussed, followed by themes of intercultural communication competence. Barriers to effective small group work are also discussed in the light of ethnic and academic cultures, and understanding one's international students is a key theme. Furthermore, acknowledging the type of language needed in the participants' disciplines is among the expected learning outcomes, as is how learning both content and 
language can be promoted by choosing suitable methods, assignments and task design. Below are some reflections concerning the module topics covered.

"I have noticed differences in thought patterns and ways of perceiving issues between business students and non-business students... When we add national/societal cultural influences to the same situation, we will find even more variation in thought patterns and perception of issues".

"It is therefore not enough as a teacher to only take into account the different cognitive abilities and knowledge of the students in the group but also the cultural differences and their impact on teaching and learning should be kept in mind in order to interact successfully in the classroom".

"I have never really stopped and considered the different challenges and issues related to teaching a multicultural group and understanding intercultural students".

\subsection{Module 3: interactive lecturing and small group teaching methods}

The expected learning outcomes for this third module include knowing how to structure and illustrate lectures through an interactive approach, and to guide small group work so that learning becomes possible at various proficiency levels. A number of studies and surveys (e.g. Braine 2002; Shaw 2013) show that teaching through English is an added cognitive and linguistic load for a non-native speaker of the language, and that new pedagogical skills and practices are required to guarantee learning in heterogeneous, multicultural and multilingual classrooms. As one of the goals is to promote learners' academic language competence, it is of the utmost importance that students are indeed given plenty of opportunities to use the language in many meaningful ways and in authentic situations (see e.g. collaborative meaning-making activities suggested by Klaassen 2001; Wells 2002; Wilkinson \& Zegers 2006). In other words, new, student-centred and interactive ways to learn and teach need to be discovered and adopted. Furthermore, it is known that appropriate pedagogical 
choices can compensate for the teachers' perhaps slightly lacking language skills and this increases the need to master several collaborative methods. TACE themes in the module are, for example, designing learning tasks for collaborative learning, cooperative learning and study skills, pragmatic awareness, and teacher talk in the classroom. In terms of the last topic, teachers in fact have to talk a significant amount in any kind of a class session, moving from classroom management and social talk for community building to expert talk and pedagogical talk (see Moate 2011). Pragmatics in our context, then, refer to the ability to adjust one's language for different purposes when using English as a second language and avoiding transfer from one's own mother tongue into English when it might cause communication breakdown (e.g. directness vs. indirectness in feedback situations). The advantages of, and possible barriers to, effective small group work are also analysed, and the TACE participants are encouraged to share their interactive and collaborative tasks and activities at the beginning of contact sessions and for the Wiki activity bank that is collected during the programme.

"The topic of small group methods on TACE was very relevant and important for me...I was mainly having lectures before".

"The topic of pragmatics was very interesting. I believe that we usually do not even think of such things as pragmatics and that quite many misunderstandings or misinterpretations could be avoided if both sides - people from different languages/cultures - would understand the pragmatic aspects of other languages from the beginning".

"During our TACE-sessions I learned to value a lot an interactive technique used by TACE teachers...this method of participation gave us as students the feeling that our experiences are valuable and accurate".

\subsection{Module 4: guiding research and academic writing}

Academic writing is in a crucial role in higher education and particularly so in international master's programmes. Students who enter these programmes 
are required from the beginning to be able to complete writing assignments demonstrating higher-order thinking skills of analysing, synthesising, evaluating information and displaying their command of disciplinary academic discourse. According to research (e.g. Braine 2002; Hunter \& Tse 2013), subject specialists are not always able to explicitly define what they require and what the assessment criteria are for written assignments. In addition, there is often no clear understanding of the students' earlier educational or academic practices, and this can lead to confusion when assigning written work such as papers, reports or essays without proper definition or instructions. The purpose of this module is to understand the differences between different academic genres of writing in various disciplines and to learn to design and assess flexible learning tasks and assignments that enable both individual and collaborative knowledge construction and active and appropriate language use at the conceptual and formal level needed.

In addition, the aim is to know how to instruct, guide and assess students' academic and research communication and how to give constructive feedback on it. The module deals with conventions and practices of academic writing, giving feedback, attending to plagiarism and most importantly, formulating instructions for assignments. The clarity of writing instructions has even been considered by the participants as a means to decrease the temptation to plagiarise. In this module, the sharing of interdisciplinary differences in research writing and reporting discourse becomes a rewarding experience, because the terms used in assignments are often vague and may have both cultural and disciplinary differences (e.g. the instructions may say 'write an essay', when the actual task is to write a report or a critical review). In addition, a crucial issue is to become aware of the distinction between fluent writing but not-so-solid content as opposed to not-so-fluent writing but solid content, because the distinction is particularly significant for a fair assessment of student achievement.

"During the meeting about writing tasks I was thinking that it is not so important to me...And now I realised how much guiding writing is actually important". 
"TACE has taught me already earlier that I must be much...more precise when I write my tasks. I showed my tasks to some of my peer students. They told me that they have no idea where to begin or what to do. I was almost shocked".

Guiding critical reading and visual literacy are also topics in this module. It is common to assign heavy reading packages for students without giving them any guidance on reading strategies or advice on critical reading. This is naturally treated in the language centre courses, but the timing is not always the best, and perhaps the content specialists could also incorporate some relevant practices in their courses. After all, being able to read critically and evaluate and synthesise research are prerequisites for good academic writing and knowledge construction.

"This links also to giving them more varied reading assignments and then linking these to purposeful tasks for students to work on. I wonder if this kind of approach would increase the students' understanding of how reading helps them with their writing".

\subsection{Module 5: alignment of teaching and assessment}

Alignment of expected learning outcomes, activities and tasks to facilitate their learning and assessment of the outcomes is a topic that is integrated and embedded in each module as a continual process. The participants are asked to bring with them the learning outcome descriptions of their course and analyse and share with their colleagues issues like recognising the linguistic and cognitive requirements of their discipline, providing appropriate tasks to achieve and assess the outcomes, as well as understanding the whole process from expected learning outcomes to assessment criteria. The alignment principle of describing the minimum level of expected learning outcomes that all students should achieve, the activities used to promote them and the assessment forms used to grade students in how well they had achieved the expected learning outcomes was adopted from Biggs (1999) and Moon (2006). In general, the TACE participants seem to actually be implicitly following the 
principle, but the use of some alternative assessment forms (e.g. learning logs) makes this more explicit. Learner involvement is also an issue often raised during this module.

"I have never formulated the goals of the course for content and language. As a student, I used to skip the goals of the course when reading a course description. As a teacher, I cared only about those goals which are directly related to the expected outcomes and their evaluation. Thus, trying to formulate the goals for the course was an interesting experience for me".

"I understand the importance of having the students interact with the course content in different ways so they can develop critical thinking".

\subsection{Module 6: using new learning environments}

Using new learning environments is also a theme that is integrated in the programme as a whole and exemplified by both teachers and by the participants themselves. During the programme itself, the TACE participants are expected and encouraged to record their reflections on teaching as well as learning processes and on experiences of modules and of sharing issues with the interdisciplinary group by writing blog posts on the platform used for the programme. Blogging is used as a tool for reflection for several reasons. First, it gives the participants a chance to comment and process information and ideas immediately after each session or module, and in this way share their thoughts, experiences and understanding of the topics covered. Second, being a fairly modern form of social media, it gives a good insight into the types of forums their students are familiar with. Finally, the platform is more flexible and interactive than what the university has been using, and therefore it was also new for the participants. Although there are some initial challenges with blogging, mainly with its practicalities, it soon becomes a tool actively employed by the participants.

"Blogging also fostered the interaction with other peers who could comment on previous reflections". 
"Blogging was a very new and challenging experience for me. Before this, I thought I liked sharing my reflections on the issues discussed in the class. However, I was surprised about how shy I used to get when it was time to post something on my Wordpress. I think it would be interesting to use blogging in my future teaching!"

"Especially what you can do with blogs, how powerful this tool can be for learning was very nicely demonstrated by the personal blogs we used".

\subsection{Module 7: TACE teaching portfolios}

The final module is concerned with creating an individual TACE teaching portfolio including one's own teaching philosophy, course plans with details on expected learning outcomes, implementation and assignment types, course assessment criteria, selected content from blog posts and, finally, the participants' evaluation of their own contribution in the TACE programme

Typically, the group decides together on what the portfolio should contain, but the participants also have much autonomy to decide themselves what they want to include and how it might serve them for example in their future professional development or as a document used to demonstrate their pedagogical merits - required by the University in, for example, staff recruitment. Judging from the outcomes, it seems that our goal of offering the participants a forum for sharing experiences, concerns and practices with colleagues across disciplines, and allocating ample time for discussions and reflections is seen as a relevant and successful approach.

"I am very happy that there was so much room given to talk with the other TACE colleagues during class. I learned so many valuable lessons from the other participants through all the fruitful discussions".

"Class discussions were invaluable for sharing practices about how to manage intercultural groups or specific challenges arising from the group 
dynamics; how to assess students' progress; how to provide constructive feedback. TACE provided the possibility to learn from the teachers' way of teaching, other participants' experiences, and provoked my own interest in finding information about the topics. I expect all this to have an impact on my future teaching".

"I have never tried to write down my teaching philosophy...It was an interesting and useful experience".

In the final contact session we also had a workshop where the participants are invited to provide feedback and offer possible development ideas and suggestions for future TACE programmes. Some of the development ideas in the past have concerned the linguistic and pedagogical terminology used in the programme. At times, more explaining would have been appreciated. Moreover, our own instructions have at times been seen as somewhat complicated by some participants, particularly at the beginning before the new jargon becomes more familiar. Both of these comments relate to interdisciplinary and intercultural issues and indicate how important it is to explain, justify and engage the students in meaningful negotiation and collaborative knowledge construction. However, the overall feedback on the programme has always been positive.

"At the beginning the English pedagogical terminology and vocabulary to describe learning designs and activities was strange to me and sometimes I even checked terms...from the dictionary and the internet. But it was also valuable because quite often I found some interesting articles and reports about those topics".

"For me TACE was really to learn how to teach, to learn pedagogy...I think my teaching grew with TACE".

"The TACE programme has been a good opportunity for me to think about my way of teaching, re-think my teaching philosophy and share experiences with people dealing with similar challenges in their work". 


\section{Concluding remarks}

Several studies have reported language and communication problems that teachers perceive in teaching their discipline in a new medium. These include such issues as lack of nuance and reduction of idiomatic expressions, lower speaking rate, lack of pragmatic strategies or problems in establishing rapport with students (Airey 2009; Dafouz \& Núnẽz 2009; Shaw 2013; Smit 2010). The TACE participants have only seldom explicitly voiced concerns such as these, although some issues about English communication skills do surface during class discussions. However, because TACE is primarily a programme in intercultural university pedagogy, and not a language programme, our emphasis has been on exemplifying talk types (Moate 2011) used in class and on promoting interactive approaches and student involvement in the teaching-learning situation. This socioconstructivist approach, advocated by Wells (2002) and others, is seen to both enhance teachers' skills in supporting learning and students' opportunity to have access to, and practice in, the use of the language and communication that characterises their discipline. Nevertheless, because discipline specialists also necessarily act as role models for disciplinary discourse, the participants have also received feedback on their academic writing assignments, class management (observations) and pronunciation, and these might become attended to even more closely if the required $\mathrm{C} 1$ level of proficiency is more formally assessed in the future.

It is often suggested that teachers teach in the way that they themselves learned in addition to implicitly following the preferences of their discipline. Although some of these preferences seemed to also exist among the TACE participants in that their instructional designs and approaches to teaching and assessment reflected interdisciplinary differences, it was also clear that there were other factors involved. Thus, as research by, for example, Oleson and Hora (2014) shows, the extent of experience of teaching and cultures, reflective practice, professional development and non-academic roles also contribute to the repertoire of teaching methods used. And, as the participant reflections indicate, sharing one's own views with colleagues representing other academic fields was one of the most appreciated aspects of the TACE programme. 
The above practice of sharing is worth considering in relation to the concept of academic freedom. It is still customary that discipline specialists, even within the same department, do not cooperate in order to provide a holistic approach to their discipline and its concepts. This means that the students get bits and pieces of the same discipline formulated in idiosyncratic ways by a number of lecturers and professors, because of the various schools of thought and paradigms within the disciplines. The disciplinary culture and discourse presented in this way can be confusing for students, and even more so when presented in a new language. The situation is naturally better in the case of more focused international master's programmes, for example, because there is usually more joint planning involved.

According to Gibbs and Coffey (2000), there is little concrete evidence that training university teachers would have any real impact. This is particularly true if the training is not based on solid conceptual grounds and empirical evidence. They further claim that

\footnotetext{
"teachers' repertoire of teaching methods is not simply an indication of their skill but of their reflection, in that if a teacher can notice differences between contexts, or can diagnose problems, then they will also use a wider repertoire of methods to respond to these problems or contexts. Someone who uses a range of methods is likely to be more reflective than someone who does not." (Gibbs \& Coffey 2000: 41)
}

This is certainly a lesson to keep in mind for both us trainers in the TACE programme and the participants, and one way of gathering the evidence needed is systematic documenting of experiences and professional development. In the case of TACE, the challenges and benefits of building knowledge and understanding through sharing and collaboration, accompanied by the reflections reported above, indicate clearly that heightened awareness of, and attention to, certain cultural, linguistic and pedagogical features apparent in multilingual and multicultural classrooms contribute to both student and teacher success, and in this way also to the quality of higher education learning and teaching. 


\section{References}

Airey, J. 2009. Science, language and literacy. Case studies of learning in Swedish university physics. Acta universitatis upsaliensis. Uppsala dissertations from the Faculty of Science and Technology 81. Uppsala Geotryckeriet.

Airey, J., Lauridsen, K. M., Räsänen, A., Salö, L. \& Schwach, V. Forthcoming. The expansion of English-medium instruction in the Nordic countries. Can top-down university language policies encourage bottom-up disciplinary literacy goals? Higher Education.

Biggs, J. 1999. Teaching for quality learning at university: what the student does. Buckingham: The Society for Research into Higher Education and Open University Press.

Braine, G. 2002. Academic literacy and the nonnative speaker graduate student. Journal of English for Academic Purposes, 1 (1), 59-68. doi:10.1016/S1475-1585(02)00006-1

Cummins, J. 1984. Wanted: a theoretical framework for relating language proficiency to academic achievement among bilingual students. In C. Rivera (ed.), Language proficiency and academic achievement. Clevedon: Multilingual Matters, 2-19.

Dafouz, E. \& Núnẽz, B. 2009. CLIL in higher education: devising a new learning landscape. In E. Dafouz \& M. Guerrini (eds.), CLIL across educational levels: experiences from primary, secondary and tertiary contexts. Madrid/London: Richmond Santillana, 101112.

Finnish Ministry of Education. 2009. Strategy for the internationalization of higher education institutions in Finland 2009-2015. Publications of the Ministry of Education. Retrieved from http://www.okm.fi/export/sites/default/OPM/Julkaisut/2009/liitteet/opm23.pdf

Flowerdew, J. \& Miller, L. 1995. On the notion of culture in L2 lectures. TESOL Quarterly, 29 (2), 345-373. doi:10.2307/3587628

Gibbs, G. \& Coffey, M. 2000. Training to teach in higher education: a research agenda. Teacher Development: An international journal of teachers' professional development, 4 (1), 31-44. doi:10.1080/13664530000200103

Hellekjaer, G. 2007. The implementation of undergraduate level English-medium programs in Norway: an explorative case study. In R. Wilkinson \& V. Zegers (eds.), Researching content and language integration in higher education. Maastricht: Universiteit Maastricht, $68-81$.

Hunter, K. \& Tse, H. 2013. Making disciplinary writing and thinking practices an integral part of academic content teaching. Active Learning in Higher Education, 14 (3), 227-239. doi:10.1177/1469787413498037 
Hyland, K. 1999. Disciplinary discourses: writer stance in research articles. In C. N. Candlin \& K. Hyland (eds.), Writing: texts, processes and practices. New York: Addison Wesley, 99-121.

Hyland, K. 2012. Disciplinary identities: individuality and community in academic discourse. Cambridge: Cambridge University Press.

Joy, S. \& Kolb, D. A. 2009. Are there cultural differences in learning style? International Journal of Intercultural Relations, 33 (1), 69-85. doi:10.1016/j.ijintrel.2008.11.002

Klaassen, R. G. 2001. The international university curriculum: challenges in English-medium engineering education. Unpublished $\mathrm{PhD}$ thesis. Delft University of Technology.

Klaassen, R. G. 2008. Preparing lecturers for English-medium instruction. In R. Wilkinson \& V. Zegers (eds.), Realizing content and language integration in higher education. Maastricht: Maastricht University, 32-42.

Kling, J. M. \& Staehr, L. S. 2011. Assessment and assistance: developing university lecturers' language skills through certification feedback. In R. Cancino, K. Jæger \& L. Dam (eds.), Policies, Principles, Practices: New Directions in Foreign Language Education in the Era of Educational Globalization. Newcastle upon Tyne: Cambridge Scholars Press, 213-245.

Light, G. \& Cox, R. 2001. Learning and teaching in higher education. The reflective professional. London: Sage.

Moate, J. 2011. Reconceptualising the role of talk in CLIL. Apples - Journal of applied language studies, 5 (2), 17-35.

Moon, J. 2006. Linking levels, learning outcomes and assessment criteria - EHEA version. Retrieved from http://spectare.ucl.slu.se/adm/sus/2008/plagiarism_eng/ JennyMoonExercise.pdf

Neumann, R., Parry, S. \& Becher, T. 2002. Teaching and learning in their disciplinary contexts: a conceptual analysis. Studies in Higher Education, 27 (4), 405-417. doi:10.1080/0307507022000011525

Oleson, A. \& Hora, M. T. 2014. Teaching the way they were taught? Revisiting the sources of teaching knowledge and the role of prior experience in shaping faculty teaching practices. Higher Education, 68 (1), 29-45. doi:10.1007/s10734-013-9678-9

Palfreyman, D. \& Mcbride, D. L. 2007. (eds.). Learning and teaching across cultures in higher education. New York: Palgrave Macmillan.

Parpala, A., Lindblom-Ylänne, S., Komulainen, E., Litmanen, T. \& Hirsto, L. 2010. Students' approaches to learning and their experiences of the teaching-learning environment in different disciplines. British Journal of Educational Psychology, 80 (2), 269-282. doi:10.1348/000709909X476946 
Parpala, A., Lindblom-Ylänne, S. \& Rytkönen, H. 2011. Students' conceptions of good teaching in three different disciplines. Assessment \& Evaluation in Higher Education, 36 (5), 549-563. doi:10.1080/02602930903541023

Pilkinton-Pihko, D. 2013. English-medium instruction: seeking assessment criteria for spoken professional English. Doctoral dissertation. Department of Modern Languages, University of Helsinki.

Räsänen, A. 2011. International classrooms, disciplinary cultures and communication conventions. Quality Assurance Review for Higher Education, 3 (2), 155-161.

Räsänen, A. \& Klaassen, R. G. 2006. From learning outcomes to staff competences in integrated content and language instruction at the higher education level. In R. Wilkinson, V. Zegers \& C. van Leeuwen (eds.), Bridging the assessment gap in English-medium higher education. AKS-Series: Fremdsprachen in Lehre und Forschung. Bochum: AKSVerlag, 256-280.

Räsänen, A. \& Klaassen, R. G. 2013. Matching student expectations and disciplinary practices - cultures in conflict? Abstract for the preconference workshop held at the ICLHE 2013 conference, Maastricht, April 10-13, 2013.

Shaw, P. 2013. Adjusting practices to aims in integrated language learning and disciplinary learning. La pédagogie de l/EMILE en questions. Recherche et pratiques pédagogiques en langues de spécialité - Cahiers de l'APLIUT, 32 (3), 16-29.

Smit, U. 2010. CLIL in an English as a lingua franca (ELF) classroom: on explaining terms and expressions interactively. In C. Dalton-Puffer, T. Nikula \& U. Smit (eds.), Language use and language learning in CLIL classrooms. Amsterdam: John Benjamins, 259-277. doi:10.1075/aals.7.13smi

University of Jyväskylä. 2004. Language Policy. Replaced in 2012.

University of Jyväskylä. 2012. University of Jyväskylä Language Policy 2012. Retrieved from http://www.jyu.fi/hallinto/strategia/en/university-of-jyvaskyla-language-policy-2012

Unterberger, B. 2012. English-medium programmes at Austrian business faculties. A status quo survey on national trends and a case study on programme design and delivery. AILA Review, 25 (1), 80-100. doi:10.1075/aila.25.06unt

Välimaa, J., Fonteyn, K., Garam, I., van den Heuvel, E., Linza, C., Söderqvist, M., Wolff, J. \& Kolhinen, J. 2013. An evaluation of international degree programmes in Finland. Finnish Higher Education Evaluation Council 2:2013. Retrieved from http://karvi.fi/en/ publication/evaluation-international-degree-programmes-finland-2/ 
Wächter, B. \& Maiworm, F. (eds.) 2014. English-taught programmes in European Higher Education. The state of play in 2014. ACA papers on international cooperation in education. Bonn: Lemmens Medien GmbH.

Wells, G. 2002. Learning and teaching for understanding: the key role of collaborative knowledge building. In J. Brophy (ed.), Volume 9 - Social constructivist teaching: affordances and constraints. Book Series: Advances in Research on Teaching, 1-41. Elsevier Science Ltd. Retrieved from http://people.ucsc.edu/ gwells/Files/Papers_Folder/ SC\%20Chapter.pdf

Wilkinson, R. 2008. Locating the ESP space in problem-based learning: English-medium degree programmes from a post-Bologna Perspective. In I. Fortanet-Gómes \& C.A. Räisänen (eds.), ESP in European Higher Education: Integrating language and content. Amsterdam: John Benjamins, 55-73. doi:10.1075/aals.4.05wil

Wilkinson, R. \& Zegers, V. 2006. The eclectic nature of assessment issues in content and language integrated higher education. In R. Wilkinson, V. Zegers \& C. van Leeuwen (eds.), Bridging the assessment gap in English-medium higher education. AKS-Series: Fremdsprachen in Lehre und Forschung. Bochum: AKS-Verlag, 25-39. 


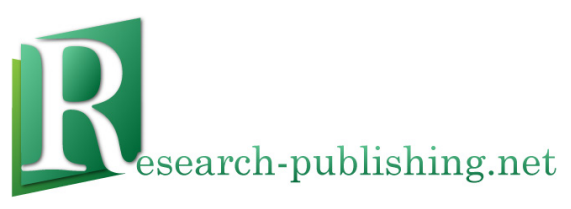

Published by Research-publishing.net, not-for-profit association Dublin, Ireland; Voillans, France, info@research-publishing.net

(C) 2015 by Research-publishing.net (collective work)

Each author retains their own copyright

Voices of pedagogical development - Expanding, enhancing and exploring higher education language learning Edited by Juha Jalkanen, Elina Jokinen, \& Peppi Taalas

Rights: All articles in this collection are published under the Attribution-NonCommercial -NoDerivatives 4.0 International (CC BY-NC-ND 4.0) licence. Under this licence, the contents are freely available online (as PDF files) for anybody to read, download, copy, and redistribute provided that the author(s), editorial team, and publisher are properly cited. Commercial use and derivative works are, however, not permitted.

\section{()ㅛ $\Theta \Theta$}

Disclaimer: Research-publishing.net does not take any responsibility for the content of the pages written by the authors of this book. The authors have recognised that the work described was not published before, or that it is not under consideration for publication elsewhere. While the information in this book are believed to be true and accurate on the date of its going to press, neither the editorial team, nor the publisher can accept any legal responsibility for any errors or omissions that may be made. The publisher makes no warranty, expressed or implied, with respect to the material contained herein. While Research-publishing.net is committed to publishing works of integrity, the words are the authors' alone.

Trademark notice: Product or corporate names may be trademarks or registered trademarks, and are used only for identification and explanation without intent to infringe.

Copyrighted material: Every effort has been made by the editorial team to trace copyright holders and to obtain their permission for the use of copyrighted material in this book. In the event of errors or omissions, please notify the publisher of any corrections that will need to be incorporated in future editions of this book.

Typeset by Research-publishing.net

Cover design by (C) Antti Myöhänen

ISBN13: 978-1-908416-25-4 (Paperback - Print on demand, black and white)

Print on demand technology is a high-quality, innovative and ecological printing method, with which the book is never 'out of stock' or 'out of print'.

ISBN13: 978-1-908416-26-1 (Ebook, PDF, colour)

ISBN13: 978-1-908416-27-8 (Ebook, EPUB, colour)

Legal deposit, Ireland: The National Library of Ireland, The Library of Trinity College, The Library of the University of Limerick, The Library of Dublin City University, The Library of NUI Cork, The Library of NUI Maynooth, The Library of University College Dublin, The Library of NUI Galway.

Legal deposit, United Kingdom: The British Library.

British Library Cataloguing-in-Publication Data.

A cataloguing record for this book is available from the British Library.

Legal deposit, France: Bibliothèque Nationale de France - Dépôt légal: septembre 2015. 